\title{
Safety, efficacy and patient satisfaction with continuous daily administration of levonorgestrel/ethinylestradiol oral contraceptives
}

This article was published in the following Dove Press journal:

Patient Preference and Adherence

29 April 2009

Number of times this article has been viewed

\author{
Giuseppe Benagiano \\ Sabina Carrara \\ Valentina Filippi \\ Department of Gynaecology \\ and Obstetrics, Sapienza University, \\ Rome, Italy
}

Correspondence: Giuseppe Benagiano 28 chemin des Massettes,

1218 Grand Saconnex, Switzerland Email giuseppe.benagiano@uniromal.it
Abstract: The progestational steroid norgestrel was synthesized and tested between 1960 and 1965 through an international cooperation between Wyeth, USA and Schering, Berlin. It is a mixture of two "enantiomers," with only one form (designated as levonorgestrel) biologically active. When taken orally, it is rapidly absorbed, not subjected to a "first-pass" effect and is approximately $90 \%$ bioavailable, with a circulating half-life around 15 hours. Its contraceptive action is exerted at the central (hypothalamic) and peripheral (cervical mucus and endometrium) levels. Levonorgestrel (LNG), alone or in combination with ethinyl estradiol (EE), is the most widely employed contraceptive progestin: it is used in combined oral contraceptives, progestogen-only pills, long-acting contraceptive implants, intrauterine contraceptive systems and in emergency contraception. It is also the steroid of choice for new oral contraceptive regimens aimed at reducing the frequency of bleeding episodes. This novel approach, already tried more than 30 years ago, gained interest around the year 2000 when surveys of women's attitudes toward monthly menstrual bleeding started to show a major change: more and more women declared that they would welcome a hormonal contraceptive method that reduced bleeding episodes to 4, 2 or even 1 per year. At this point, while the debate on the significance and "usefulness" of menstruation went on, attention focused on new regimens. The first new modality consisted of changing the 7-day medication-free interval, either shortening it to fewer than 7 days, or by the administration of low-dose estrogens during the interval between packages. Then, continuous administration regimens started to be investigated. This, however, did not happen suddenly, since, in specific situations, doctors had for years empirically utilized various continuous administration regimens. The first extendedcycle oral contraceptive regimen introduced in clinical practice is an 84-day regimen that results in bleeding only 4 times a year. A commercial product specifically packed for continuous use is now available in Europe and contains $30 \mu \mathrm{g}$ EE and $150 \mu \mathrm{g}$ LNG. In a variation of this regimen, after administration of the same combination for 84 days, women are given 7 pills containing $10 \mu \mathrm{g}$ EE. A 6-monthly regimen has also been tested in a small study using EE $20 \mu \mathrm{g}$ plus LNG $100 \mu \mathrm{g}$ taken with and without a hormone-free interval. Women in the continuous group reported significantly fewer bleeding days requiring protection and were more likely to have amenorrhea; in addition they also reported significantly fewer days of bloating and menstrual pain. A yearly regimen is now being developed. Each pill of this novel formulation contains EE $20 \mu \mathrm{g}$ and LNG $90 \mu \mathrm{g}$ to be taken continuously for 364 days ( 13 cycles) per year. A phase III trial has now evaluated safety, efficacy and menses inhibition. At the end of the 1-year trial amenorrhea was present in $58.7 \%$ of the women and a complete absence of bleeding in $79.0 \%$. Overall, the number of bleeding and spotting days per pill pack declined with time and adverse events and discontinuations were comparable to those reported for cyclic oral contraceptive regimens.

Keywords: levonorgestrel, oral contraceptive, continuous administration, menstruation, amenorrhea 


\section{Introduction}

The short, but intense history of hormonal contraception is usually reconstructed chronologically, from the fundamental discoveries in reproductive physiology at the turn of the 19 th century that set the stage (eg, see $\left.{ }^{1-3}\right)$, to the synthesis of various generations of progestins (eg, see $\left.{ }^{4,5}\right)$.

Today, however, it is possible to redesign in a logical fashion the physiological and pharmacological paths that led to the present variety of methods; the starting point for such a "new history" is the discovery by O'Malley and his group of estrogen and progesterone receptors (ER, PR). ${ }^{6}$ The reason is simple: synthetic progestins belong to the large family of progesterone receptor ligands and they represent the agonists within the group of compounds known today as selective progesterone receptor modulators, or SPRMs. This family includes pure agonists, such as progesterone itself and all synthetic progestins and, at the other end of the spectrum, pure antagonists. The so-called "true SPRMs" have mixed agonist-antagonist properties and occupy an intermediate position in the spectrum. ${ }^{7}$

In vivo, SPRMs exert clinically relevant tissue-selective effects on various progesterone target tissues and these effects may differ depending on the biological action studied. ${ }^{8,9}$ This feature has an important clinical application, since all receptor modulators bind to more than one receptor: for instance, progesterone antagonists bind to the antiglucocorticoid receptor, ${ }^{10}$ whereas synthetic progestins may bind to one or more steroid receptors depending on their structure. ${ }^{5}$ This means that, in selecting a hormonal contraceptive for an individual woman, a physician should guide her choice by pointing out the metabolic and pharmacodynamic profile of different compounds, thereby helping the woman in the selection of the product with the most favorable characteristics.

It is for this reason that, in reviewing available clinical data on the contraceptive modality known as "continuous daily administration" of combined oral contraceptives containing levonorgestrel, one must start summarizing its metabolic characteristics and biological action.

\section{Norgestrel and levonorgestrel}

The progestational steroid norgestrel was synthesized and tested between 1960 and 1965 through an international cooperation between Wyeth (Madison, NJ, USA) and Schering (today Bayer-Schering Healthcare, Berlin, Germany); ${ }^{11}$ its chemical structure is $( \pm)-13 \beta$ ethyl-17 $\beta$-hydroxygon-4-en3-one, identifying it as a derivative of gonane (a theoretical steroid skeleton molecule not existing in nature) (see Figure 1).

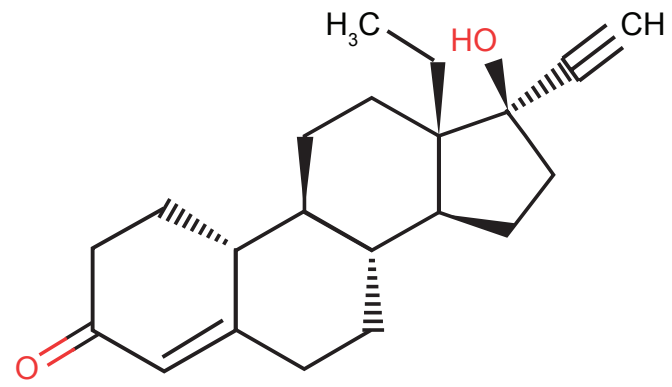

Figure I Norgestrel:8R,9S, I0R, I3S, I4S, I 7S- I3-ethyl- I7-ethynyl- 17-hydroxy- I, 2, 6, 7, $8,9,10,11,12,14,15,16$-dodecahydrocyclopenta[a]phenanthren-3-one.

It is a mixture of two "enantiomers," a particular form of stereoisomers that are mirror images of each other and are identical in all their physical properties, with the exception that they rotate the plane of polarized light in opposite directions. To distinguish between the two enantiomers the chemical classification that considers the effect of polarized light, assigned the prefix (d), or the sign (+) to the dextrorotatory form, whereas the prefix (1) or (-) was given to the levo-rotatory one; finally the racemic mixture was designated as (dl) or $( \pm)$ norgestrel. Another classification, however, based exclusively on the absolute configuration of a given compound, defines enantiomers as $(d)$ if they have the same configuration as carbon-10 of cholesterol and as $(l)$ (both in italics) if they possess the opposite configuration. ${ }^{12}$ Only one of the two enantiomers is biologically active and this active form was initially designated as "d-norgestrel" because only the $\mathrm{d}(-)$ form, contained in $50 \%$ of the racemate, is biologically active; later, however, chemists insisted that the active compound be designated as " $l$-norgestrel" (in italics) because the absolute configuration must prevail. ${ }^{13}$

In view of the fact that, ever since it became possible to separate the two enantiomers, only the active form has been utilized, it quickly became clear that the chemically correct nomenclature could cause confusion among clinicians; for this reason, the World Health Organization, Special Programme of Research in Human Reproduction (WHO-HRP) recommended that the active levo-rotatory enantiomer of the racemic mixture be designated as levonorgestrel (LNG), or $\mathrm{d}(-) l-17 \beta$-hydroxy-17 $\alpha$-ethinyl-13 $\beta$-ethyl-4-gonen-3-one.

\section{Pharmacodynamics of levonorgestrel}

The pharmacodynamics of progestogens vary a great deal depending on the compound and the route of administration. In terms of ovulation inhibition, the most potent progestin available today is gestodene, with a daily ovulation-inhibiting dose of $40 \mu \mathrm{g} .{ }^{4}$ 
Relative potencies of the most widely utilized progestins are shown in Table 1. They have been classified as belonging to several different "generations," as shown in Figure 2.

When taken orally, LNG is rapidly absorbed, is not subject to a "first-pass" effect and is approximately $90 \%$ bioavailable with a circulating half-life around 15 hours. ${ }^{12}$ After oral ingestion of $150 \mathrm{mg}$, peak plasma levels around $2 \mathrm{ng} / \mathrm{mL}$ are obtained between 1 and 3 hours, but LNG is still detectable in circulation at 48 hours. Its $\mathrm{LD}_{50 \mathrm{i}}$ is $>5000 \mathrm{mg} / \mathrm{kg} .{ }^{14}$ When circulating, $47.5 \%$ is bound to sex hormone binding globulin (SHBG), $50 \%$ to albumin, while $2.5 \%$ is unbound..$^{15}$ When bound to progesterone receptor in the hypothalamus, levonorgestrel is capable of slowing gonadotropin releasing hormone $(\mathrm{GnRH})$ pulse release, quenching the pre-ovulatory luteinizing hormone (LH) surge. Eventually, this phenomenon results in ovulation inhibition. ${ }^{16}$

As already mentioned, like every other progesterone agonist, it binds to several steroid receptors. Its in vitro relative binding affinities are: ${ }^{16}$

- for the progesterone receptor, $323 \%$ that of progesterone;

- for the androgen receptor, $58 \%$ that of testosterone;

- for the mineralocorticoid receptor, $17 \%$ that of aldosterone;

- for the glucocorticoid receptor, $7.5 \%$ that of cortisol;

- for the estrogen receptor, $<0.02 \%$ that of estradiol.

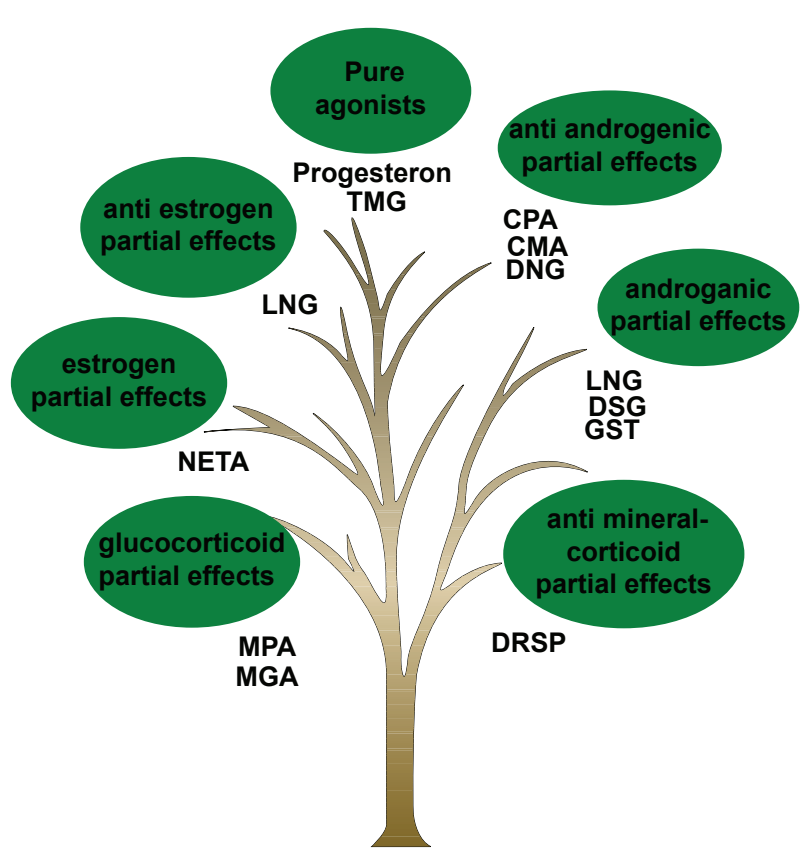

Figure 2 The "Progestogen Tree."

Abbreviations: CMA, chlormadinone acetate; CPA, cyproterone acetate; DNG, dienogest; DRSP, drospirenone; DSG, desogestrol; GST, gestodenes; MGA megestrol acetate; LNG, levonorgestrol; MPA, medroxyprogesterone acetate; NETA; norethindrone acetate;TMG, trimegestone

Courtesy Prof. A Genazzani, University of Pisa, Italy.

\section{Mechanism of contraceptive action of levonorgestrel}

All contraceptive progestins possess a double mechanism of action: at the central and at the peripheral level, although the relative importance of a particular mechanism in ensuring proper contraceptive protection depends on the route of administration. ${ }^{4}$

Taking into account the synergistic action of the estrogen, when combined with 30 to $35 \mu \mathrm{g}$ of ethinyl estradiol (EE) levonorgestrel can block fertility by inhibiting ovulation at the daily oral dose of $60 \mu \mathrm{g}$ (corresponding to peak plasma levels of approximately $1 \mathrm{ng} / \mathrm{mL}$ ). This inhibitory action is mainly exerted at the hypothalamic level where, physiologically, progesterone decreases the number of LH pulses. ${ }^{16,17}$ At level of the endometrium, when given orally, LNG produces an inactive or atrophic endometrium; however, after discontinuation of hormonal exposure, there is a rapid return to normal endometrial cycling. ${ }^{18} \mathrm{~A}$ different picture appears when LNG is delivered directly to the uterine cavity; in this case there is extensive decidualization of endometrial stromal cells, atrophy of the glandular and surface epithelium and changes in vascular morphology (suppression of spiral artery formation and presence of large, dilated vessels). There is also modulation of local mediators regulating endometrial function. ${ }^{19}$ In addition, local delivery of LNG seems to overpower the priming effect of endogenous estradiol $\left(\mathrm{E}_{2}\right)$ and in fact, circulating levels of estradiol are within the same range, irrespective of whether women are menstruating or amenorrheic, pointing to a purely local effect of LNG that cannot be influenced by $\mathrm{E}_{2}{ }^{20}$

Table I Biological activity of different progestogens, using two different tests

\begin{tabular}{lll}
\hline & $\begin{array}{l}\text { Ovulation } \\
\text { inhibiting dose } \\
\text { (mg/die) }\end{array}$ & $\begin{array}{l}\text { Endometrial } \\
\text { transformation } \\
\text { (mg/cycle) }\end{array}$ \\
\hline Progesterone & $>10$ & 60 \\
Dihydrogesterone & $>30$ & 140 \\
MPA & 10 & 80 \\
Lynestrenol & 2 & 70 \\
Chlormadinone ac & 1.5 & $20-30$ \\
Cyproterone ac & 1 & 20 \\
Noretisterone & 0.5 & $100-150$ \\
Norgestimate & 0.2 & 2 \\
Desogestrel & 0.06 & 6 \\
Levonorgestrel & 0.05 & 7 \\
Gestodene & 0.04 & 2 \\
\hline
\end{tabular}

Abbreviations: MPA, medroxyprogesterone ac. 
A different local action is evident even when LNG is administered at doses that do not constantly inhibit ovulation; under such circumstances a progestin can still remain effective as a contraceptive by acting at the level of the cervical mucus, by significantly decreasing the amount, ferning and spinnbarkeit of cervical mucus, while at the same time increasing viscosity. Under the effect of progestins, cervical mucus scores do not exhibit the normal mid-cycle peak, cervical mucus receptivity to sperm is lowered, sperm penetration in cervical secretion is inhibited and the ovulatory peak of the karyopknotic index of vaginal cytology is suppressed. Finally, when the mucus is observed by scanning electron microscopy, it resembles that seen at the end of pregnancy or during menopause. ${ }^{4}$ After insertion of subcutaneous LNG-delivering implants (Norplant) cervical mucus score decreases within one week, indicating the profound effect of LNG on cervical mucus, even in the event of possible ovulation. ${ }^{21}$

\section{Levonorgestrel-containing hormonal contraceptives}

Levonorgestrel is the most widely utilized contraceptive progestin, alone or in combination with EE. Marketed for the first time in the 1960s, LNG can be found today in combined oral contraceptives (COC), progestin-only pills, long-acting contraceptive implants, intrauterine contraceptive systems and in the most widely utilized emergency contraceptive modality. A list of marketed preparations containing LNG is presented in Table 2 .

A remarkable feature of products listed in Table 2 is the progressive decrease in dosage that took place in COCs containing LNG and EE. This reflects efforts to minimize adverse reactions due to either the progestin or the estrogen component of the pill.

In this connection, when COCs containing the so-called third-generation progestins (desogestrel, gestodene and norgestimate) were first marketed, the pharmaceutical industry stressed their metabolic "neutrality" and, for a period of time, it looked as if these COCs would eventually replace those containing LNG.

Then, in 1995, a WHO-sponsored study comparing risk of venous thrombo-embolism (VTE) with second- and third-generation progestins ${ }^{22}$ found a doubling of the risk of VTE in users of COCs containing third-generation compounds. A subsequent meta-analysis conducted by Kemmeren et al. ${ }^{23}$ established a relative risk of VTE of 1.7 for use of COCs with third- versus second-generation progestins. It is important to recall that an increased risk of VTE in women
Table 2 Hormonal contraceptives containing norgestrel or levonorgestrel

\begin{tabular}{ll}
\hline Combined oral contraceptives \\
Monophasic \\
NGS & $500 \mu \mathrm{g}+\mathrm{EE} 50 \mu \mathrm{g}$ \\
NGS & $500 \mu \mathrm{g}+\mathrm{EV} 2 \mathrm{mg}$ \\
NGS & $300 \mu \mathrm{g}+\mathrm{EE} 30 \mu \mathrm{g}$ \\
LNG & $250 \mu \mathrm{g}+\mathrm{EE} 50 \mu \mathrm{g}$ \\
LNG & $125 \mu \mathrm{g}+\mathrm{EE} 50 \mu \mathrm{g}$ \\
LNG & $250 \mu \mathrm{g}+\mathrm{EE} 30 \mu \mathrm{g}$ \\
LNG & $150 \mu \mathrm{g}+\mathrm{EE} 30 \mu \mathrm{g}$ \\
LNG & $100 \mu \mathrm{g}+\mathrm{EE} 20 \mu \mathrm{g}$ \\
Phasic & \\
LNG & $50 / 150 \mu \mathrm{g}+\mathrm{EE} 50 \mu \mathrm{g}$ \\
LNG & $20 / 150 \mu \mathrm{g}+\mathrm{EE} 30 / 40 \mu \mathrm{g}$ \\
LNG & $50 / 75 / \mathrm{I} 25 \mu \mathrm{g}+\mathrm{EE} \mathrm{30/40/30 \mu g}$ \\
Progestin-only pills & \\
LNG 75 $\mu \mathrm{g}$, daily without interruption \\
Subcutaneous implants \\
Norplant I \\
Norplant 2 (Jadelle) \\
Sinoimplant I \\
Sinoimplant 2
\end{tabular}

Abbreviations: EE, ethinyl estradiol; EV, estradiol valerate; NGS, norgestrel; LNG, levonorgestrel.

using COCs has been reported since $1969^{24}$ and is today accepted as a fact, since it has been documented in all large studies conducted since then; the odds ratio (OR) of VTE is about four for any COC use. ${ }^{25}$ This finding led to renewed interest in oral contraceptives containing LNG to the point that this progestin was selected as the compound to be utilized in the majority of studies of new administration modalities aimed at reducing the number and duration of menstrual episodes.

Several reasons can be cited for this choice: a long, successful clinical experience with levonorgestrel has documented its safety; in the US (where experience with new progestin molecules is much more limited than in Europe) randomized studies have shown that LNG-containing products have better bleeding patterns than those containing norethisterone; ${ }^{26-28}$ and in Europe, the controversy over the above-mentioned increase in VTE with newer progestins has not yet been resolved.

\section{Effectiveness}

\section{Attitudes towards menstruation}

When, in the 1950s and 1960s, Pincus and his team developed the first hormonal contraceptive, its administration schedule 
was selected purely for the convenience of women, although, as early as 1958, Pincus wrote that, with hormonal contraceptives, "a cycle of any desired length could presumably be produced." ${ }^{29}$ In spite of this, for 50 years, with the exception of a small number of subjects like young athletes, women were happy with their "artificial menstruations" coming at regular 28-day intervals, because the belief that "menstruating once a month is good for you" remained part of most cultures around the world. This reality constituted, at least initially, a major stumbling block in modifying the administration schedule to decrease the number of yearly bleeding episodes, since it was assumed that, for a majority of women word wide, a contraceptive method resulting in fewer bleeds or amenorrhea would be poorly acceptable. Even half a century ago, however, some women felt that artificially decreasing the frequency of bleeding would eliminate the adverse symptomatology that sometimes precedes or is associated with it. Therefore, at least for them, new contraceptive regimens reducing the number of annual menstrual episodes down to one may be a welcome development. With time, at least in industrialized countries, their number steadily grew till it seemed large enough to warrant attention by the pharmaceutical industry.

\section{The evolution of attitudes towards menstruation}

The report of a recent ESHRE (European Society of Human Reproduction and Embryology) Capri Meeting ${ }^{30}$ reminds us that periodic vaginal bleeding from the uterus is characteristic of humans, old world primates and a small number of other mammals. Bleeding results from shedding of the endometrial lining of the uterus at the end of a non-fertile ovarian cycle and is conditioned by the presence of uterine spiral arterioles; Finn ${ }^{31}$ was the first to speculate that, in species that menstruate, a degree of decidualization of the endometrium during the luteal phase occurs even in the absence of an embryo and that endometrial shedding can occur only from decidual tissue.

Whatever the physiological mechanisms involved, menstruation carries a series of clinical consequences that range from a minor inconvenience, to a major health concern for those who suffer from menstrual disorders and health conditions that are aggravated during their menstrual cycle. ${ }^{32}$ It has been calculated that between $20 \%$ and $40 \%$ of women consider their cyclic bleeding as a negative experience, often leading to impairment in the conduct of even ordinary business. ${ }^{33}$

Apart from clinical effects, in every society menstruation is surrounded by customs and traditions, with a wide range of reactions by individual women, as well as society as a whole, to an event that, throughout the ages, has been given positive and negative connotations. For instance, menarche, the onset of menses at puberty, is considered in some cultures as a public event, with festivities celebrating the onset of fertility and a sign of the transition from girlhood to womanhood. In other cultures, however, menstruating women are considered unclean, dangerous and even poisonous. These contrasting reactions represent the ambivalent attitudes of society and individual women to menstruation. ${ }^{32,34}$

\section{Positive features of menstrual bleeding}

Traditionally there are two main reasons why women believe it is important to bleed at monthly intervals; these motives have been thoroughly discussed by O'Grady. ${ }^{34}$

The first is that with menstrual blood women eliminate both retained fluid and "body impurities" and, in acceptance of that principle, Hippocrates stated that: "menstruation was designed to cleanse women of bad humors." During the Roman times, Galen proposed that if menstruation is the natural means by which a body cures itself of ills, an ailing person may be treated by a physician-initiated blood-letting. ${ }^{35}$

It seems that prejudices and misconceptions about menstrual flow, associating it with something "impure" or even "dangerous" to be eliminated from the body, have been present in every culture across the globe. This is reflected in religious practices requiring "purification" after a menstrual bleeding. For instance, Orthodox Jewish women observing the laws of family purity, abstain from physical contact with their husbands from the onset of menses until 7 days after their cessation; at this point the woman must take a ritual bath, after which she may resume physical and sexual relations with her husband..$^{36}$ In the Islamic tradition, menstruating women are exempt from some important religious rites, such as ritual prayers, fasting, and the pilgrimage to Mecca. However, whereas sexual intercourse is prohibited during menses, all other forms of physical contact between husband and wife, for example, hugging and kissing, are allowed. ${ }^{37}$

As pointed out by $\mathrm{O}^{\prime} \mathrm{Grady},{ }^{34}$ it is possible that the old idea of "impurities" or even "toxic agents" present in menstrual blood might have been reinforced by the physical discomfort that often precedes and accompanies menses. For the modern and educated women these misconceptions are almost completely outmoded, although in individual cases, old beliefs can still act unconsciously, aggravating and even originating cases of premenstrual syndrome and dysmenorrhea.

The second main reason for welcoming a monthly bleed is represented by the so-called "signal of fertility theory," 38 according to which the occurrence of menses serves as a 
signal: to the woman that she is not pregnant, or infertile; and to the man that his female will soon be fertile again. It is for this reason that, as already mentioned, when hormonal contraception was developed, given the lack of early and sensitive pregnancy tests, pill administration was designed with pill-taking for 21 days followed by a 7-day free interval, to allow periodic bleeding at the time women expected it. ${ }^{39}$

In discussing the advantages of monthly bleedings, the question to be asked is "why do women bleed" and, indeed, theories on why menstruations occur and should be welcome, abound. From an evolutionary standpoint it seems almost obvious that there should be a functional purpose for regular menstruation, or it would have neither appeared, nor survived during the course of evolution. In 1993, Profet, ${ }^{38}$ an evolutionary biologist, proposed her "theory of menstruation," according to which bleeding occurs to cleanse the female reproductive tract of potentially harmful bacteria that may have entered the female reproductive tract with sperm. These would be neutralized by the active presence in menstrual blood of macrophages; in her view, "menstruation functions to protect the uterus and oviducts from colonization by pathogens." From her perspective, cessation of menses would be harmful to a woman's health rather than beneficial. This theory did not go unchallenged, with two opposite arguments being put forward: some argued that, on the contrary, menstrual blood may represents an ideal pabulum for sexually transmitted micro-organisms and that a woman is more susceptible to vaginal infections during menstruation than at any other time in her cycle. ${ }^{40}$ Houppert, from studies conducted on a variety of reproductive tract conditions (from toxic shock syndrome, to infertility and endometriosis), concluded that these ailments may be, at least in part, caused by trace levels of dioxins found in most tampons and pads. According to this hypothesis, modern "management" of menstruation may in fact interfere with a natural immune process. ${ }^{41}$ Adding to this, Strassmann ${ }^{42,43}$ suggested that the function of endometrial cyclicity is energy savings: since endometrial function is temporally restricted to when fertilization occurs, it would be more costly to sustain this tissue when it is not needed, than to regenerate it in each cycle. Thus, blood loss is only a side-effect. She has calculated that "endometrial economy" preserves the metabolic equivalent of 6 days' worth of food for women.

\section{Negative aspects of menstruation}

Nowadays, more and more people believe that menstruation is simply the sign that the process of reproduction has failed and, for the sake of reproductive efficiency, this process has to be repeated month after month, until a successfully nested fertilized egg starts to develop. ${ }^{35}$ If this is true, the main reasons for considering menstruation as a positive sign, is that it takes place when pregnancy does not. However, this argument may be utilized to reach very different conclusions.

Some, like Coutinho and Segal ${ }^{35}$ have gone as far as to define regular menstruation as "unnatural," since in the early times, "young women were either pregnant or lactating almost continuously." In this respect, it has been calculated that, from the days of primitive foraging societies to the 20th century, the mean number of menstrual bleeds a woman would experience during her fertile age, increased from 160 to $450 .{ }^{44}$ Therefore, "from a medical point of view, menstruation has no beneficial effects for anyone, and for many women it is harmful to their health." ${ }^{45}$

This means that menstruation has been viewed as "unhealthy" both from a medical (Houppert) and an anthropological (Coutinho and Segal) viewpoint. Reviewing all these data, O'Grady ${ }^{34}$ concluded that "it may be less that menstruation 'causes' the onset of infectious diseases ... than that our 'treatment' of menstruation interferes with a natural immune process."

It is beside the scope of this review to analyze in depth the origin and meaning of menstruation. Clearly, the issue has not yet been settled to the point that Emily Martin ${ }^{46}$ believes that, to this day, normative paradigms continue to present male functions as the norm, with differences observed in females seen as aberrations from a male "norm": to people following this "philosophy" menstruation cannot be a positive phenomenon.

\section{Bleeding irregularities}

While sociologists, gynecologists and anthropologists may differ in their appraisal of menstruation, everyone agrees that irregular bleeding (and more specifically heavy bleeding) is a major public health problem, besides being one of the main reasons why women discontinue certain hormonal methods of contraception (specifically, those containing only a progestin). Indeed, every year some $5 \%$ of all women in US aged 30 to 49 years consult their physician for bleedingrelated problems. ${ }^{47}$

As pointed out in the already mentioned ESHRE document, ${ }^{30}$ menstrual disorders significantly interfere with the quality of life and each year they cause the loss of millions of work-days with enormous costs being incurred for treatment. Bleeding irregularities are more common near the beginning and end of the fertile life, due to the frequent occurrence of anovulatory cycles. 
Given these facts, many women have welcome COCs, a modality capable or guaranteeing cyclic withdrawal bleeding to the vast majority of users. In addition, a specific administration schedule that allows less frequent bleeding is likely to be welcome, at least by women troubled by menstrual disorders.

\section{Acceptability of amenorrhea in different cultures}

As shown above, until recently a majority of health professionals have safely assumed that women would prefer to menstruate at regular monthly intervals and, from the early days of hormonal contraception, ${ }^{48}$ a contraceptive method is to be considered ideal only if it allows regular monthly withdrawal bleedings; as a consequence, amenorrhea had to be considered an undesirable side effect. This concept was reinforced by large surveys of women's attitudes towards menstruation carried out during the 1970 s by the WHOHRP. These investigations concluded that the proportion of women who were prepared to use a method of contraception causing amenorrhea, ranged from $47 \%$ in UK to only $10 \%$ in Pakistan. ${ }^{49}$

In spite of the widespread desire for regular menses, progestin-only contraceptives (such as depot medroxyprogesterone acetate, or DMPA), which have been credited to cause "menstrual chaos," are perfectly acceptable to women in a number of developing countries..$^{50,51}$

Clearly, the cultural context plays an important role even within the same country. For instance, a study carried out in the US showed that black women are generally more conservative and significantly fewer black than white women consider acceptable a contraceptive modality abolishing monthly bleeds. Indeed, two thirds of white women did not like monthly bleeds and would prefer bleeding-free intervals ranging from 90 days to complete amenorrhea. Among these women, $40 \%$ were ready to consider using a hormonal contraceptive that stops menstruations altogether, with the other $60 \%$ either unwilling or undecided. ${ }^{52}$

The existence of important attitudinal differences between women of different cultures has been highlighted in several multinational, comparative studies. A first, pioneering survey, published in $2003^{53}$ involved women in Nigeria, South Africa, Scotland and China. Only among black women in Africa did the majority like having periods. In the other groups most women disliked periods, which were "inconvenient" and associated with menstrual problems. For this reason, these women would be willing to try a contraceptive that induces amenorrhea. In another study comparing attitudes towards menstruation in the US, Brazil and Germany, when asked about their ideal non-bleeding interval, approximately one-third of the respondents in the US and Brazil declared to prefer not to bleed at all, whereas less than $10 \%$ of women sampled in Germany favored this option. In all three countries, the proportion of women who indicated a preference for bleeding every 6 months was substantially lower than the corresponding proportion of women who preferred to bleed every 3 months. In all countries women felt that the most common positive features of having menses were: being assured of not being pregnant; feeling healthier; and feeling lighter. Conversely, the most common negative features of menstruation were cramps, bad mood, inconvenience before and during menses (eg, premenstrual syndrome). ${ }^{54}$

Studies involving only European women show a trend towards a more positive attitude vis-à-vis amenorrhea. For instance, in the Netherlands a survey published in 1999 indicated that only around $30 \%$ of the women wanted to have periods every month; about $25 \%$ did not want to have periods any more and the rest wanted to modify the frequency of their periods to occur at 3-6- or 12-month intervals. ${ }^{55}$ In France, only $11 \%$ of women involved in a large survey carried out in 2005 liked to have their periods every month; 75\% considered menstruation to be a constraint. When specifically asked whether they would take a pill that would prevent them from bleeding, 57\% responded positively. ${ }^{56}$ In a study of Italian women published in 2006, among 270 women without menstruation-related symptoms, more than 50\% stated that they would like to change the rhythm of their periods, with $28 \%$ wishing longer intervals between bleedings and 29\% not to have menses at all. ${ }^{57}$ Contrary to the results obtained in the previously mentioned multicenter study ${ }^{54}$ a survey published in 2004 showed that only $26 \%$ to $35 \%$ of German women preferred monthly bleeding, while $37 \%$ to $46 \%$ wished not to have menses at all. Those wishing not to bleed cited, as positive outcomes, relief from severe menstrual complaints, better hygiene, higher quality of life, and less blood loss. Among women preferring regular withdrawal bleeding when using a $\mathrm{COC}$, the main reasons for their choice were the fact that menstruation is a normal phenomenon, fear of pregnancy, fear of infertility and possible adverse effects of continuous regimens. ${ }^{58} \mathrm{~A}$ more conservative attitude seems to be still prevalent among Spanish women: In a just published study, among 588 women aged between 18 and 45 years, only 5\% expressed interest in using a continuous oral contraceptive regimen. This percentage increased to nearly $50 \%$ in women below 25 years. ${ }^{59}$ 
Finally, a survey conducted in Australia more than 20 years ago, which evaluated knowledge, attitudes and practices of young women concerning menstruation, menstrual protection and menstrual cycle problems, indicated that the young women, as a group, lacked sufficient information about menstruation, time of ovulation, menstrual discharge, and even the use of tampons. A high proportion (80\%) considered menstruation to be inconvenient or embarrassing. ${ }^{60}$

\section{New administration regimens for combined oral contraceptives containing levonorgestrel}

As early as 1977, the group of Roger Short and Malcolm Potts showed that reducing withdrawal bleedings to four times a year (using an oral contraceptive containing EE $50 \mu \mathrm{g}$ plus lynestrenol $2.5 \mathrm{mg}$ ) was both acceptable and effective: $82 \%$ of the women welcomed fewer menstrual bleeds and the parallel reduction in menstrual and premenstrual symptoms, and many found the tri-cycle regimen easier to follow. Menstrual loss was unchanged, or simply reduced in all but seven women. Interesting enough, according to the authors, "doctors and nurses on the clinic staff were less enthusiastic about this regimen than the volunteers themselves." ${ }^{\prime 61}$

This study, however, remained an isolated attempt for more than 20 years, and it was only when developments in hormonal contraception produced COCs in which the estrogen daily dose had reached the minimum feasible and after the introduction of a series of new progestins, that the attention of developers switched to novel administration schedules.

Initially, attention focused on changing the 7-day medication-free interval and, some 10 years ago, a 24-day regimen followed by a hormone-free interval of only 4 days was tested and introduced into clinical practice. The first such preparation contains EE $15 \mu \mathrm{g}$ plus gestodene $60 \mu \mathrm{g} ;{ }^{62}$ others followed: one is made up of EE $20 \mu \mathrm{g}$ plus drospirenone $2 \mathrm{mg} .{ }^{63}$ The second contains EE $20 \mu \mathrm{g}$ plus drospirenone $1 \mathrm{mg} .{ }^{64}$

More recently, however, new options have been considered to decrease the frequency of free intervals or to eliminate them altogether. ${ }^{39}$

After Thomas and Ellertson ${ }^{65}$ stated in 2000 that it might be time to give women the choice of "if and when to menstruate," Andrist et al ${ }^{66}$ added that, since pharmacological methods to safely "manipulate" menstrual cycles now exist, it is high time to investigate new options. As already pointed out, in specific situations various continuous administration regimens have been empirically recommended by doctors: for instance, in young athletes, or in the event of marriage, the 21-day regimen has been extended to permit the withdrawal bleeding to occur away from the event. In addition, extended pill use (with or without interruption) has also been advocated as a maintenance treatment for endometriosis-associated pelvic pain in women not wishing to become pregnant, ${ }^{67,68}$ to avoid menstruationassociated symptoms, such as migraine headache ${ }^{69}$ and premenstrual syndrome. ${ }^{65}$ In addition, Martin-Johnston et a ${ }^{70}$ found that there is an increased number of reproductive age women at risk for thrombocytopenia and, they too, would benefit from menses suppression.

Data on continuous administration regimens began to appear with the new millennium and in 2001, Miller ${ }^{71}$ reported the first study on the continuous daily administration of LNG $(100 \mu \mathrm{g})$ and EE $(20 \mu \mathrm{g})$ for the "elimination of menses." No pregnancies were observed in 94 subjects.

\section{Trimonthly regimens}

The first formulation specifically packed for continuous use was marketed in the US under the trade name of Seasonale ${ }^{\circledR}$ by Duramed Pharmaceuticals Inc., a subsidiary of Barr Pharmaceuticals, Montvale, New Jersey. It contains $30 \mu \mathrm{g}$ EE and $150 \mu \mathrm{g}$ LNG. The package comes in a 3-monthly supply. Women take one active pill per day for 84 days (12 weeks) and then take an inactive pill for 7 days. ${ }^{72}$ This regimen allows a reduction from 13 to 4 bleeding episodes per year; however, during the first 8 or 9 months of use, women taking the COC continuously are about twice as likely as those using conventional regimens to experience breakthrough bleedings. Two clinical trials have evaluated this new regimen. ${ }^{73,74}$ In the second, the longer-term study, overall, 189 women were enrolled from 27 clinical sites and treated with Seasonale ${ }^{\circledR}$. Of these women, 103 (54\%) were from the first study, whereas the remaining women had previously been assigned to one of the other COC therapies evaluated in that trial. As this was primarily a long-term safety study, no formal efficacy evaluation was planned other than a simple calculation of the proportion of treated patients who became pregnant. At any rate, no pregnancy was reported.

A variation of this regimen, named Seasonique ${ }^{\circledR}$ consists of a continuous administration of the same combination for 84 days, followed by 7 pills containing $10 \mu \mathrm{g}$ EE instead of a pill-free interval. This preparation has been tested for safety and efficacy in some 700 women. ${ }^{75} \mathrm{~A}$ Pearl Index of 1.27 was calculated, with adverse reactions causing the discontinuation of $16 \%$ of the subjects. Withdrawal bleeding occurred in the majority of cases, in spite of the presence of low dose estradiol during the interval period; this was attributed to the progestin withdrawal. This regimen may be an option for 
women who experience bleeding/spotting during the use of an extended, 3-monthly cycle regimen

Other combinations are now being tested: after the introduction of a COC containing EE $20 \mu \mathrm{g}$ and drospirenone $2 \mathrm{mg}$ as a 21-day regimen this combination is now being tried for possible utilization for 120 days without interruption. Preliminary data indicate a positive effect on the so-called pre-menstrual dysphoric disorder and on endometriosisassociated pain. ${ }^{76,77}$ Given its positive profile, this new "trimonthly pill" will soon become available in Europe.

Data are now accumulating on women perception after taking extended-cycle oral contraceptives. A survey conducted in the US in 2002 , found that $41 \%$ of women of fertile age (18 to 49 years), would prefer never to menstruate, with the highest preference in the 40- to 49-year-old group. Only 29\% of the women felt that it was necessary to menstruate once per month and, when asked why they preferred this option, the reply was that bleeding serves as confirmation that a woman is not pregnant. ${ }^{78}$ In a second, recent survey, $80.5 \%$ of currently menstruating women preferred one or more changes in bleeding pattern (eg, less pain, shorter and lighter bleeds, or amenorrhea). In addition, the majority of women in all age groups preferred to have longer intervals between bleeding. ${ }^{79}$

Another study focused on adolescents and found that an overwhelming majority of them $(96.6 \%)$ view unexpected bleeding negatively; therefore, extended regimens seem particularly attractive to this group of women. ${ }^{80}$ Finally, even the attitude of health professionals who, in the past have been found to be more conservative than their patients, seems to be changing. When, in 2006, Sulak et al surveyed a group of health-care professionals (primary care physicians, obstetrician/gynecologists, nurse practitioners and physician assistants), about their attitudes toward prescribing extendedcycle COCs, a total of $81 \%$ of those asked reported that they have recommended extending the number of active pills in the traditional oral contraceptive $21 / 7$ regimen. ${ }^{81}$

In addition to acceptability, Schwartz et al have also addressed the question of cost-effectiveness of extended cycle regimens. They found that the economic savings for patient out-of-pocket expenses from decreased sanitary product usage, as a result of nine fewer withdrawal bleeding episodes, is offset by the cost of three extra packages of COCs. They concluded that the tri-monthly schedule may be cost-effective for women with menorrhagia. ${ }^{82}$

\section{Six-monthly regimens}

In 2003, Kwiecien et al published the first, small study aimed at evaluating in a comparative fashion bleeding patterns and acceptability of EE $20 \mu \mathrm{g}$ plus LNG $100 \mu \mathrm{g}$ taken with and without a hormone-free interval. Thirty-two women were randomized to six 28-day cycles or 168 days without a pill-free interval. Women in the continuous group reported significantly fewer bleeding days requiring protection and were more likely to have amenorrhea, as shown in Figure 3. There were no pregnancies and, given the small group of women involved, the observed decrease in total bleeding days did not reach statistical significance. However, women in the continuous group reported significantly fewer days of bloating and menstrual pain. ${ }^{83}$ The authors concluded that both methods of administration have equivalent subjective acceptability.

\section{Annual regimen}

Following the already mentioned first trial by Miller, ${ }^{71}$ Miller and Hughes ${ }^{84}$ published the results of a new comparative study in which 79 women were randomized to either classic 28-day cycles (21 active pills and a pill-free week) or to 12 cycles (336 days) of continuous use of a preparation containing LNG $100 \mu \mathrm{g}$ and EE $20 \mu \mathrm{g}$. A first important outcome of the study was the difference in continuation rates: $70 \%$ (28 subjects) for the 28-day cycle and $82 \%$ (71) for the continuous-use subjects. With continuous use, 49\%, 68\% and $88 \%$ of the women reported no bleeding during cycles 2, 6 and 12, respectively, while amenorrhea or infrequent bleeding was present in $68 \%$ of continuous users during cycles 1 to 3 and increased to $88 \%$ during cycles 10 to 12 . Spotting initially increased in continuous users, but reduced over time, and by 9 months was less than the spotting reported by cyclic users. No pregnancy was reported and the incidence

Amenorrhea

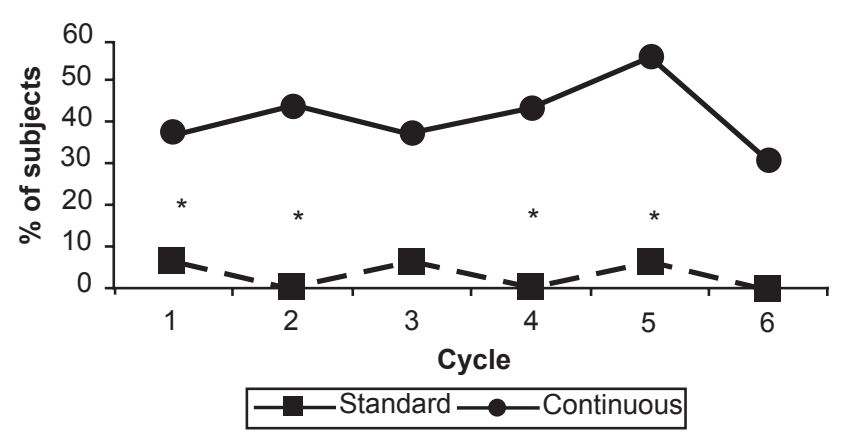

Figure 3 Percentage of subjects reporting no bleeding in each treatment cycle. Asterisks indicate significant difference $(p=0.05)$ within a cycle.

Reproduced with permission from Kwiecien M, Edelman A, Nichols MD, Jensen JF. Bleeding patterns and patient acceptability of standard or continuous dosing regimens of a low-dose oral contraceptive: a randomized trial. Contraception. 2003;67:9-13. ${ }^{83}$ Copyright (c) 2003 Elsevier. 
of adverse events, blood pressure, weight, and hemoglobin findings was similar between groups.

Once the acceptability of "no bleeding" regimens was ascertained, developers focused their attention on the continuous administration over 1 year of a LNG-containing pill. This resulted in the development and clinical testing of a not-yet-marketed formulation meant for women who would like to avoid bleeding altogether. Each pill contains EE $20 \mu \mathrm{g}$ and LNG $90 \mu \mathrm{g}$ and is to be taken continuously for 364 days/year. It is distributed in packages containing 28 tablets. It has been given the trade name of Lybrel $^{\circledR}$, and is being developed by Wyeth Corp. (Madison, NJ, USA). Recently, a study was conducted to evaluate the safety, efficacy and menses inhibition with this continuous daily regimen in 2402 women, of whom 921 completed the study, while 2134 took the preparation for at least 1 month. The protocol included two sub-studies to assess cycle-related symptoms and endometrial histology. A first paper was recently published summarizing the safety and efficacy results of the phase 3 trial and evaluated menses inhibition. At the end of the 1-year trial (Pill Pack 13), results showed that amenorrhea was present in $58.7 \%$ of women and a complete absence of bleeding in $79.0 \%$. This terminology may be confusing, since usually amenorrhea is defined as the complete absence of bleeding. Overall, the number of bleeding and spotting days per pill pack declined with time; adverse events and discontinuation rates were comparable to those reported for cyclic COC regimens, except for higher rates in effects related to uterine bleeding. The Pearl Index method failure was 1.26, and user failure was 0.34 . While on Pill Pack 13, 58.7\% of subjects reported amenorrhea and $79.0 \%$ reported absence of bleeding. Overall, the number of bleeding and spotting days per pill pack declined progressively. Adverse events and discontinuations were comparable to those reported for cyclic oral contraceptive regimens, except for higher rates in those related to uterine bleeding. Authors concluded that the continuous administration of the LNG/EE pill indicates a good safety profile and efficacy similar to that of cyclic COCs: The regimen continuously inhibited menses, increased the incidence of amenorrhea over time and, except for a subset of women, decreased the number of bleeding and spotting days.$^{85}$ Results of the morphological paper are also available for 93 volunteers who completed at least 6 pill packs and for whom a baseline biopsy was available. Before treatment, $60 \%$ had an endometrial biopsy with findings classified as "weakly proliferative or proliferative". At the last visit, $52 \%$ of the subjects had an endometrium categorized as "other," which included primarily an "inactive" or "benign" endometrium. No hyperplasia or malignancy was observed during the study ${ }^{86}$ This study indicates a good endometrial safety profile.

Interestingly enough, the availability of this new administration schedule provoked a heated debate even before the combination had a chance to be marketed. Indeed, on April 20, 2007, The New York Times ran an article by Stephanie Saul pointing to the ambivalence women feel about taking a drug that will suppress monthly bleedings. She spoke of a "complex love-hate relationship" women have with their period, something denied by the manufacturer. The company collected data in the US through a questionnaire and found out that women's interest toward this pill depended on a personal approach to monthly periods. Indeed, $50 \%$ of the women they surveyed said that they welcomed their periods as an indicator that they were not pregnant and 25\% said that their periods were a natural part of womanhood. In contradistinction, two-thirds of the same women supported the idea of avoiding monthly bleeds. ${ }^{87}$ The debate heated up when some feminist groups accused the manufacturer of misogyny. Pretty soon the Web filled-up with activists arguing that women may wish to get rid of menstruation to please their partners, or to look more like men.

What seems to have been lost in the debate is the fact that this particular pill will be taken only by women who wish to become amenorrheic; under the circumstances, its availability cannot possibly be considered as "violence" against women's attitudes or beliefs.

\section{Comparison between continuous and cyclic administration}

A recent Cochrane review analyzed data on cyclic versus continuous administration of LNG-containing COCs. ${ }^{88}$ It compared contraceptive efficacy, compliance, continuation, satisfaction, bleeding profile and menstrual symptoms of combined oral contraceptives with continuous regimens (ie, $>28$ days of active pills). Interestingly, not only contraceptive efficacy but also compliance were similar between groups. Also, overall discontinuation, and that for bleeding problems, were not evenly distributed between the two groups. In general, participants reported high satisfaction with both types of regimens. As expected, the group with continuous administration had greater improvement of menstrual-associated symptoms (headache, genital irritation, tiredness, bloating, and menstrual pain).

Lack of sufficient information prevents a true comparison between continuous administration regimens and, in 2007, Steinauer and Autry stated: "Although we do not have enough 
data to recommend one particular extended cycle regimen over another, the use of these new regimens will provide women with more options, and almost certainly will improve the acceptability and efficacy of hormonal contraception." 89

\section{Conclusions}

Continuous daily administration of oral hormonal contraceptives containing levonorgestrel and ethinyl estradiol (for 3 or 6 months, or 1 year) is still in a preliminary stage of clinical testing. Indeed, although two 3-monthly preparations have been marketed, limited information is available. Nonetheless, these new administration schedules seem well accepted by women, safe and effective.

\section{Disclosures}

The authors declare no conflicts of interest.

\section{References}

1. Goldzieher JW, Rudel HW. How the oral contraceptives came to be developed. J Am Med Assoc. 1974;230:421-425.

2. Diczfalusy E. The contraceptive revolution. Caserton Hall: The Parthenon Publishing Group; 1997.

3. Benagiano G, Isidori C. Le basi razionali per l'utilizzazione clinica di una associazione estro-progestinica contenente Gestodene. In: Aggiornamenti in scienze ginecologiche ed ostetriche. Fioretti P, Melis GB Editors. Roma: CIC Edizioni Internazionali; 1987. p. 295-304.

4. Benagiano G, Farris M, Primiero FM. Clinical profile of contraceptive progestins. Eur J Contracept Reprod Health Care. 2004;9:182-193.

5. Ware RS. New progestagens for contraceptive use. Hum Reprod Update. 2006;2:169-178

6. Smith CL, O'Malley BW. Coregulator function: a key to understanding tissue specificity of selective receptor modulators. Endocr Rev. 2004;25:45-71.

7. Chabbert-Buffet N, Meduri G, Bouchard P, Spitz IM. Selective progesterone receptor modulators and progesterone antagonist: mechanism of action and clinical applications. Hum Reprod Update. 2005; 11(3):293-307.

8. Spitz IM, Chwalisz K. Progesterone receptor modulators and progesterone antagonists in women's health. Steroids. 2000;65:807-815.

9. Chwalisz K, Perez MC, DeManno D, Winkel C, Schubert G, Elger W. Selective Progesterone Receptor Modulator. Development and Use in the Treatment of Leiomyomata and Endometriosis. Endocrine Rev. 2005;26:423-438.

10. Spitz IM, Croxatto HB, Robbins A. Antiprogestins: mechanism of action and contraceptive potential. Annu Rev Pharmacol Toxicol. 1996;36:47-81.

11. Schering AG. Hormonal Contraception. 3rd Ed. London: Butler \& Tanner; 2001. p. 109.

12. Stanczyk FZ, Roy S. Metabolism of levonorgestrel, norethindrone, and structurally related contraceptive steroids. Contraception. 1990;42:67-96.

13. Sanchez-Borregol R, Balasci J. Ethinyl oestradiol plus dl-norgestrel or levonorgestrel in the Yuzpe method for post-coital contraception: results of an observational study. Hum Reprod. 1996;11:2449-2453.

14. Fotherby K, Caldwell ADS. New progestogens in oral contraception. Contraception. 1994;49:1-31.

15. Schindler AE, Campagnoli C, Druckmann R, et al. Classification and pharmacology of progestins. Maturitas. 2003;46 Suppl 1:S7-S16.

16. Stanczyk FZ. Structure-function relationships, potency, and pharmacokinetics of progestogens. In: Lobo RA, editor. Treatment of the postmenopausal woman: basic and clinical aspects. New York: Raven Press; 1994. p. 69-89.
17. Scleusser E, Broeckner T, Brautigam J, Michaels W. Influence of two low dose oral contraceptives on possible gonadotropin secretion. Gynecol Endocrinol. 2001;15:259-264.

18. Anderson FD, Hait H, Hsiu J, Thompson-Graves AL, Wilborn WH, Williams RF. et al. Endometrial microstructure after long-term use of a 91-day extended-cycle oral contraceptive regimen. Contraception. 2005;71:55-59.

19. Guttinger A, Critchley HO. Endometrial effects of intrauterine levonorgestrel. Contraception. 2007;75 Suppl 6:S93-S98.

20. Luukkainen T. Levonorgestrel-releasing intrauterine device. Ann NY Acad Sci. 1991;626:43-49.

21. Dunson TR, Blumenthal PD, Alvarez F, et al. Timing of onset of contraceptive effectiveness in Norplant implant users. Changes in cervical mucus. Fertil Steril. 1998;69:258-266.

22. World Health Organization Collaborative Study of Cardiovascular Disease and Steroid Hormone Contraception. Venous thromboembolic disease and combined oral contraceptives: results of international multicentre case-control study. Lancet. 1995;346:1575-1582.

23. Kemmeren JM, Algra A, Grobbee DE. Third generation oral contraceptives and risk of venous thrombo-embolism. BMJ. 2001;323:1-9.

24. Sartwell PE, Masi AP, Arthes G, et al. Thromboembolism and oral contraceptives: an epidemiologic case-control study. Am J Epidemiol. 1969;90:365-380.

25. Martínez F, Avecilla A. Combined hormonal contraception and venous thromboembolism. Eur J Contracept Reprod Health Care. 2007;12:97-106.

26. Endrikat J, Hite R, Bannemerschult R, Gerlinger C, Schmidt W. et al. Multicenter, comparative study of cycle control, efficacy and tolerability of two low-dose oral contraceptives containing $20 \mathrm{mcg}$ ethinylestradiol/100 mcg levonorgestrel and $20 \mathrm{mcg}$ ethinylestradiol $/ 500$ mcg norethisterone. Contraception. 2001;64:3-10.

27. Reisman H, Martin D, Gast MJ. A multicenter randomized comparison of cycle control and laboratory findings with oral contraceptive agents containing $100 \mathrm{mcg}$ levonorgestrel with $20 \mathrm{mcg}$ ethinyl estradiol or triphasic norethindrone with ethinyl estradiol. Am J Obstet Gynecol. 1999;181:45-52.

28. Chavez A, DelConte A. A comparison of cycle control with monophasic levonorgestrel/ethinylestradiol $100 \mathrm{micrograms} / 20$ micrograms versus triphasic norethindrone/ethinylestradiol 500750-1000 micrograms/35 micrograms: a multicenter, randomized, open label study. Eur J Contracept Reprod Health Care. 1999;4: 75-83.

29. Pincus, G. Control of fertility. New York and London: Academic Press; 1965. p. 219

30. The ESHRE Capri Workshop Group; Apter D, Baird DT, Collins J, et al. Report prepared by Collins J, Crosignani PG. Endometrial bleeding. Hum Reprod Update. 2007;13:421-431.

31. Finn CA. Implantation, menstruation and inflammation. Biol Rev. 1986;61:313-328.

32. Lin $\mathrm{K}$, Banhart $\mathrm{K}$. The clinical rationale for menses-free contraception. $J$ Womens Health (Larchmt). 2007;16:1171-1180.

33. Drife JO. Menstruation: a cultural and historical perspective. In: Cameron IT, Fraser IS, Smith SK, Editors. Clinical disorders of the endometrium and the menstrual cycle. Oxford and London: Oxford University Press; 1998. p. 312.

34. O'Grady K. Canadian Women's Health. Available from: http// www. cwhn.ca.

35. Coutinho EM, Segal SJ. Is menstruation obsolete? New York: Oxford University Press; 1999.

36. Berkowitz B. Cultural aspects in the care of the orthodox Jewish woman. J Midwifery Womens Health. 2008;53:62-67.

37. Dhami S, Sheikh A. The Muslim family: predicament and promise. West J Med. 2000;173:352-356.

38. Profet M. Mestruation as a defence against pathogen transported by sperm. Q Rev Biol. 1993;68:335-386.

39. Sulak PJ. Continuous oral contraception: changing times. Best Pract Res Clin Obstet Gynaecol. 2007;20:1-20. 
40. Strassmann BI, Gillespie B. Life-history theory, fertility and reproductive success in humans. Proc R Soc Lond B. 2002;262:553-562.

41. Houppert K. The curse: confronting the last unmentionable taboo: Menstruation. New York: Ferrar, Straus and Giroux; 1999.

42. Strassmann BI. The Evolution of endometrial cycle and menstruation. Q Rev Biol. 1996;71:181-220.

43. Strassmann BI. Energy economy in the evolution of menstruation. Evol Anthropol. 1997;5:158-164.

44. Eaton SB, Wood JW, Pike MC, et al. Women's reproductive cancers in evolutionary context. Quart Rev Biol. 1994;69:353-367.

45. Segal, SJ. Preface to Coutinho EM, Segal SJ. Is menstruation obsolete? New York: Oxford University Press; 1999. p. XIII.

46. Martin E. The woman in the body: a cultural analysis of reproduction. Boston: Beacon Press; 1987.

47. Garside D, Gann PH, Gapstur SM, et al. the effects of a low-fat/ high-fiber diet on sex hormone levels and menstrual cycling in premenopausal women. Wiley InterScience. 2004;98:1870-1879.

48. Pincus G, Garcia CR, Rock J. Effects of certain 19-nor-steroids on the normal human menstrual cycle. Science. 1956;124:891-893.

49. World Health Organisation Task Force on Psychosocial Research in Family Planning Geneva. WHO; 1981.

50. Pardthaisong T. McDaniel EB, Gray RH. Acceptance and use of Depo Provera in Chieng Mai. IPPF Med Bull. 1975;9:1-3.

51. Edelman A, Lew R, Cwiak C, Nichols M, Jensen J. Acceptability of contraceptive-induced amenorrhea in a racially diverse group of US women. Contraception. 2007;75:450-453.

52. Kaunitz AM. Menstruation: choosing whether ... and when. Contraception. 2000;62:277-284.

53. Glasier AF, Smith KB, van der Spuy ZM, et al. Amenorrhea associated with contraception-an international study on acceptability. Contraception. 2003;67:1-8.

54. Snow R, Hardyb E, Kneuperc E, et al. Women's responses to menses and non-bleeding intervals in the USA, Brazil and Germany. Contraception. 2007;76:23-29.

55. Tonkelaar I, Oddens BJ. Preferred frequency and characteristics of menstrual bleeding in relation to reproductive status, oral contraception use, and hormone replacement therapy use. Contraception. 1999;59:357-362.

56. SOFRES. Reproduction Humaine et Hormones, Symptômes liés au cycle: doivent-ils rester une fatalité? Résultat d'une grande enquête miroir TNS Sofres, Médecins/patientes sur l'attitude vis à vis des règles et la prise en charge des symptômes liés aux cycles. SOFRES Survey. 2006;19(no. 8 Spécial):1-11.

57. Ferrero S, Abbamonte LH, Giordano M, et al. What is the desired menstrual frequency of women without menstruation-related symptoms? Contraception. 2006;73:537-541.

58. Wiegratz I, Hommel HH, Zimmermann T, Kuhl H. Attitude of German women and gynecologists towards long-cycle treatment with oral contraceptives. Contraception. 2004;69:37-42

59. Sánchez-Borrego R, García-Calvo C. Spanish women's attitudes towards menstruation and use of a continuous, daily use hormonal combined contraceptive regimen. Contraception. 2008;77:114-117.

60. Abraham S, Fraser I, Gebski V, et al. Menstruation, menstrual protection and menstrual cycle problems. The knowledge, attitudes and practices of young Australian women. Med J Aust. 1985;142: $247-251$

61. Loudon NB, Foxwell M, Potts DM, Guild AL, Short RV. Acceptability of an oral contraceptive that reduces the frequency of menstruation: the tri-cycle pill regimen. Br Med J. 1977;2:487-490.

62. Sullivan H, Furniss H, Spona J, Elstein M. Effect of 21-day and 24-day oral contraceptive regimens containing gestodene $(60 \mu \mathrm{g})$ and ethinyl estradiol $(15 \mu \mathrm{g})$ on ovarian activity. Fertil Steril. 1999;72: 115-120.

63. Bachman G, Sulak PJ, Sampson-Landers C, et al. Efficacy and safety of a low-dose 24-day combined oral contraceptive containing 20 micrograms ethinylestradiol and $3 \mathrm{mg}$ drospirenone. Contraception. 2004;70:191-198.
64. Nakajima ST, Archer DF, Ellman H. Efficacy and safety of a new 24-day oral contraceptive regimen of norethindrone acetate $1 \mathrm{mg} /$ ethinyl estradiol $20 \mathrm{mg}$ (Loestrin-24 Fe). Contraception. 2007;75:16-22.

65. Thomas SL, Ellertson C. Nuisance or natural healthy: should monthly menstruation be optional for women? Lancet. 2000;355:922-924.

66. Andrist LC, Arias RD, Nucatola D, et al. Women's and providers' attitudes toward menstrual suppression with extended use of oral contraceptives. Contraception. 2004;70:359-363.

67. Benagiano G, Pera A, Bianchi P. Management of endometriosis: Historical background and rationale for the use of steroid hormones. In: Lemay A, Maheux R, Editors. Understanding and managing endometriosis. Advances in research and practice. New York: Parthenon Publishing; 1999. p. 211-218

68. Vercellini P, De Giorgi O, Mosconi P, Stellato G, Vicentini G, Crosignani PG. Cyproterone acetate versus a continuous monophasic oral contraceptive in the treatment of recurrent pelvic pain after conservative surgery for symptomatic endometriosis. Fertil Steril. 2002; 77:52-61.

69. MacGregor A. Migraine associated with menstruation. Funct Neurol. 2000;15:143-153.

70. Martin-Johnston MK, Okoji OY, Armstrong A. Therapeutic amenorrhea in patients at risk for thrombocytopenia. Obstet Gynecol Surv. 2008;63:395-402.

71. Miller L. Continuous administration of $100 \mathrm{mcg}$ levonorgestrel and 20 mcg ethinyl estradiol for elimination of menses: a randomized trial. Obstet Gynecol. 2001;97:S16.

72. Kaunitz AM. Beyond the pill: New data and options in hormonal and intrauterine contraception. Am J Obstet Gynecol. 2005;192:998-1004.

73. Anderson FD, Hait H. and The Seasonale-301 Study Group. A multicenter, randomized study of an extended cycle oral contraceptive. Contraception. 2003;68:89-96.

74. Anderson FD, Gibbons W, Portman D. Long-term safety of an extendedcycle oral contraceptive (Seasonale): a 2-year multicenter open-label extension trial. Am J Obstet Gynecol. 2006;195:92-96.

75. Anderson FD, Gibbons W, Portman D. Safety and efficacy of an extended regimen oral contraceptive utilizing continous low-dose ethinyl estradiol. Contraception. 2006;73:229-234.

76. De Berardis D, Serroni N, Salerno RM, Ferro FM. Treatment of premenstrual dysphoric disorder (PMDD) with a novel formulation of drospirenone and ethinyl estradiol. Ther Clin Risk Manag. 2007;3: $585-590$.

77. Fenton C, Wellington K, Moen-Robinson D.M. Drospirenone/ethinylestradiol $3 \mathrm{mg} / 20$ microg (24/4 day regimen): a review of its use in contraception, premenstual dysphoric disorder and moderate acne vulgaris. Drugs. 2007;67:1749-1765.

78. Association of Reproductive Health Professionals. Extended regimen oral contraceptives. Harris Poll, June 14-17, 2002.

79. den Tonkelaar I, Odden BJ. Preferred frequency and characteristics of menstrual bleeding in relation to reproductive status, oral contraceptive use, and hormone therapy replacement use. Contraception. 1999;59:357-362.

80. Omar H, Kives S, Allen L. Extended use of the oral contraceptive pill - is it an acceptable option for the adolescent? J Pediatr Adolesc Gynecol. 2005;18:285-288.

81. Sulak PJ, Buckley T, Kuehl TJ. Attitudes and prescribing preferences of health care professionals in the United States regarding use of extended-cycle oral contraceptives. Contraception. 2006;73:41-45.

82. Schwartz JL, Creinen MD, Pymar HC. The trimonthly combination oral contraceptive regimen: is it cost effective? Contraception. 1999;60:263-267.

83. Kwiecien M, Edelman A, Nichols MD, Jensen JF. Bleeding patterns and patient acceptability of standard or continuous dosing regimens of a low-dose oral contraceptive: a randomized trial. Contraception. 2003;67:9-13.

84. Miller L, Hughes JP. Continuous combination oral contraceptive pills to eliminate withdrawal bleeding: a randomized trial. Obstet Gynecol. 2003; 101:653-661. 
85. Archer DF, Jensen JT, Johnson JV, Borisuted H, Grubb GS, Constantine GD. Evaluation of a continuous regimen of levonorgestrel/ethinyl estradiol: phase 3 study results. Contraception. 2006;74:439-445.

86. Johnson JV, Grubbs GS, Constantine GD. Endometrial histology following 1 year of a continuous daily regimen of levonorgestrel $90 \mathrm{microg} / \mathrm{ethinyl}$ oestradiol $20 \mathrm{microg}$. Contraception. 2007;75:23-26.
87. Kaiser Daily Women's Health Policy Report 5/22/2007.

88. Edelman A, Gallo MF, Nichols MD, Jensen JT, Schulz KF, Grimes DA. Continuous versus cyclic use of combined oral contraceptives for contraception: systematic Cochrane review of randomized controlled trials. Hum Reprod. 2006;21:573-578.

89. Steinauer J, Autry AM. Extended cycle combined hormonal contraception. Obstet Gynecol Clin North Am. 2007;34:43-55.

\section{Publish your work in this journal}

Patient Preference and Adherence is an international, peer-reviewed, open access journal that focusing on the growing importance of patient preference and adherence throughout the therapeutic continuum. Patient satisfaction, acceptability, quality of life, compliance, persistence and their role in developing new therapeutic modalities and compounds to optimize clinical outcomes for existing disease states are major areas of interest. This journal has been accepted for indexing on PubMed Central. The manuscript management system is completely online and includes a very quick and fair peer-review system. Visit http://www.dovepress.com/ testimonials.php to read real quotes from published authors.

Submit your manuscript here: http://www.dovepress.com/patient-preference-and-adherence-journal 